\title{
Management and outcome of pregnancy in autoimmune hepatitis
}

\author{
M A Heneghan, S M Norris, J G O’Grady, P M Harrison, I G McFarlane
}

\begin{abstract}
Background-There is a paucity of data in the literature on the risks associated with, and optimal management of, pregnancy in patients with autoimmune hepatitis (AIH).

Aims-To assess maternal and fetal outcomes in relation to clinical management of pregnancy in a large cohort of patients with well defined AIH.

Methods-A review of all known pregnancies in 162 females with definite AIH attending our clinics between 1983 and 1998, with respect to treatment, natural history, and outcome.

Results-Thirty one live births (one twin) resulted from 35 pregnancies in 18 women (seven with cirrhosis). Median age at conception was 28 years (range 18-36). Two patients presented with AIH de novo during pregnancy. At conception, in 15 pregnancies patients had been receiving azathioprine alone or (in nine) with prednisolone, in seven prednisolone alone, and in one cyclosporin. Fetal loss at $\geqslant 20$ weeks' gestation occurred in two instances. Flares in disease activity occurred during four pregnancies and within three months of delivery in a further four. Among the 31 children born (median follow up 10 years) only two abnormalities have been identified: Perthes' disease in one and severe mental and physical handicap in a second who was born prematurely following decompensation of the mother's liver disease. Neither mother was receiving azathioprine.

Conclusions-Successful completion of pregnancy is a realistic expectation for patients with well controlled AIH. Treatment options vary, but azathioprine appears to be generally safe and without adverse outcomes for mother or baby. Vigilance is required, however, and patients need to be monitored carefully during pregnancy and for several months post partum.

(Gut 2001;48:97-102)
\end{abstract}

Keywords: pregnancy; liver disease; autoimmune disease; azathioprine; corticosteroids

Present address: Division of Gastroenterology, Box 3923, Duke University Medical Centre, Durham, NC 27710 USA

Correspondence to: Dr I G McFarlane. ian.mcfarlane@kcl.ac.uk

Accepted for publication 8 August 2000 Autoimmune hepatitis (AIH) is a disorder of unknown aetiology in which progressive destruction of the hepatic parenchyma occurs, frequently leading to cirrhosis. The syndrome has been recognised for more than 40 years and its characteristic features have been extensively reviewed. ${ }^{1-4}$ In severe cases it carries a high mortality if untreated but the large majority of patients show a good response to immunosuppressive drugs and, since the 1970 s, corticosteroids with or without azathioprine have been the mainstay of therapy for patients with AIH. ${ }^{5-11}$

Amenorrhoea and anovulation are common in women with established cirrhosis, and pregnancy was previously reported to be relatively rare. ${ }^{12}{ }^{13}$ An early observation in patients with $\mathrm{AIH}$ was an association between reduced fertility and the presence of other endocrine disorders, ${ }^{14}$ while a more recent study suggested that amenorrhoea might be related to hypothalamic-pituitary dysfunction. ${ }^{15}$ None the less, in these patients menstruation can occur once disease activity lessens and, with improvements in the clinical management of $\mathrm{AIH}$, pregnancies are becoming more common. However, little is known of the evolution of AIH during pregnancy or maternal and fetal outcomes. The most comprehensive study, published 20 years ago, documented a high incidence of obstetric complications, including toxaemia of pregnancy, premature delivery, low birth weight, and a high caesarean section rate, ${ }^{13}$ but a recent case report noted spontaneous resolution of AIH during pregnancy. ${ }^{16}$

Additionally, there has been concern about clinical management during pregnancy because of the risk to both mother and fetus associated with relapse of AIH. Corticosteroids seem to be generally safe but the safety of azathioprine in pregnancy is less certain. The side effect profile of azathioprine in pregnant mice and rabbits has included the development of skeletal abnormalities, cleft palate, reduced thymic size, hydrops fetalis, anaemia, and haematopoietic depression in the fetus. ${ }^{17}{ }^{18} \mathrm{Al}-$ though these consequences have never been reported in humans, animal experiments have dissuaded the use of azathioprine in pregnant patients. Thus most clinicians generally advise women receiving azathioprine against pregnancy and recommend that the drug should be discontinued during pregnancy, or even that pregnancies should be terminated in certain instances. ${ }^{19-21}$ None the less, there have been several reports of normal pregnancies in patients with systemic lupus erythematosus or inflammatory bowel disease, and in transplant recipients receiving azathioprine. ${ }^{17} 1^{182-29}$

Because there is still a paucity of data on

Abbreviations used in this paper: $\mathrm{AIH}$, autoimmune hepatitis; AST, aspartate aminotransferase; ANA, antinuclear antibodies; SMA, smooth muscle antibodies; anti-LKM1, liver-kidney microsomal antibodies. 
have undertaken a retrospective analysis of the outcome of pregnancies in women with AIH attending King's College Hospital, with particular emphasis on maternal and fetal outcomes and with the aim of evaluating the efficacy and safety of the treatment regimens utilised in the pregnancies.

\section{Patients and methods}

A regularly updated database of AIH patients attending the Institute of Liver Studies at King's College Hospital London since 1983 was interrogated. Up to the end of 1998,162 females who had been regularly followed up during this study period were identified who fulfilled criteria for definite $\mathrm{AIH}$ as defined by the International Autoimmune Hepatitis Group. ${ }^{24}$ Of these, 83 were aged less than 50 years and 68 less than 45 years. At accession, all had moderate to severe interface hepatitis on liver biopsy. Eighteen had reported being pregnant at any time and these comprised the present study cohort. Sixteen of these had type $1 \mathrm{AIH}$, with antinuclear (ANA) and/or smooth muscle (SMA) autoantibody titres ranging from $1: 40$ to $1: 2560$ (median $1: 160$ ) and two (patients Nos 5 and 6, table 1) had type 2 disease, both with anti-liver-kidney microsomal (anti-LKM1) antibody titres of 1:2560 at presentation. Seven had biopsy proven cirrhosis and 11 were non-cirrhotic at conception. Median age at diagnosis of AIH was 19 years (range 3-33) and median duration of follow up since diagnosis was 14 years (range 4-27). There were no significant differences between cirrhotic and non-cirrhotic patients with respect to age at presentation (median $18.5 \mathrm{v}$ 20.5 years, respectively) or duration of disease (median $14.5 \approx 13.5$ years). The records of these women were systematically reviewed with respect to their progress during their pregnancies, including therapy, development of complications, and maternal and fetal outcomes.

The remaining 50 patients aged less than 45 years (24 with cirrhosis) served as a control group. Forty five had type $1 \mathrm{AIH}$ with the same median and range of ANA and/or SMA titres at presentation as the pregnancy group and five had type 2 AIH (median anti-LKM1 1:320; range 1:160-1:1280). Median age at diagnosis in the control group was 28 years (range 9-44) and median duration of follow up was 11 years (range 3-28). There were no significant differences from the pregnancy group with respect to these parameters.

For the purpose of this study, a flare of hepatitis was defined as a twofold increase in serum aspartate aminotransferase (AST) activity above the upper normal limit $(\leqslant 50 \mathrm{IU} / \mathrm{l})$ or a lesser increase in AST in conjunction with increased serum globulin concentration (upper normal limit $35 \mathrm{~g} / \mathrm{l}$ ) and the re-emergence of symptoms, as defined previously. ${ }^{11}$ The study was undertaken with informed consent of patients and under the supervision of the local ethics committee in accordance with the 1975 Helsinki Declaration guidelines.
STATISTICAL ANALYSIS

All data are expressed as median (range). The Wilcoxon signed ranks test was used for comparison of pairs of data at different time points and the $\chi^{2}$ test with Yates' correction for small numbers was used for dichotomous variables. A two tailed probability ( $p$ ) value less than 0.05 was considered significant.

\section{Results}

Thirty five pregnancies were reported by 18 women. Median age at conception (all pregnancies) was 28 years (range 18-36). In two patients (Nos 15 and 18, table 1), AIH was diagnosed de novo during their pregnancies. In the remainder, median duration of disease at the time of pregnancy was eight years (range 1-27). One patient reported termination of a pregnancy at six weeks' gestation for reasons unconnected with her disease. Two others reported early miscarriages, one within the first trimester and the other at 14 weeks' gestation. Details of the remaining 32 pregnancies are summarised in table 1 . Thirty one live births resulted from these 32 pregnancies, including one successful twin pregnancy in a cirrhotic patient.

Conception was achieved by in vitro fertilisation in three pregnancies, without prior discussion with a hepatologist. One was in a woman with cirrhosis (patient No 11) who had a full term delivery without any complications or deterioration in liver function throughout the pregnancy. The other two were in one (patient No 18) of the two cases diagnosed de novo and were associated with major complications which are discussed below. Apart from this one patient, where emergency caesarean section was required in her first pregnancy (see below), delivery was vaginal in all completed pregnancies (including the twins).

THERAPEUTIC REGIMENS DURING PREGNANCY At conception, in nine pregnancies patients were receiving combination therapy (prednisolone $5-10 \mathrm{mg} /$ day with azathioprine at $1 \mathrm{mg} / \mathrm{kg} / \mathrm{day}$ in eight and at $2 \mathrm{mg} / \mathrm{kg} / \mathrm{day}$ in one), six others were receiving azathioprine alone (four at $2 \mathrm{mg} / \mathrm{kg} /$ day and two at $1 \mathrm{mg} / \mathrm{kg}$ / day), seven were receiving prednisolone alone (5-15 mg/day), and one was being treated with cyclosporin. In nine pregnancies, patients were receiving no treatment at the time of conception. Two of these related to the two cases of de novo presentation, and four were in two patients whose AIH had been diagnosed in childhood and following successful treatment had sustained remission for $7-14$ years without therapy. Of the remaining three, in one instance the patient had stopped treatment herself three months before conception, in the second the patient had initially declined treatment, and in the third there had been an apparently spontaneous biochemical remission (although a subsequent relapse required institution of prednisolone). Among the treated patients, median duration of treatment with azathioprine prior to conception was 7.2 years (range 1-17) and for prednisolone therapy 6.0 years (range 1-17). Azathioprine was withdrawn in 
three instances (three months to two years prior to conception) in women on combination therapy who were planning to become pregnant, and remission was sustained with prednisolone alone. In two others (both unplanned pregnancies), azathioprine was gradually withdrawn over a four week period during the first trimester.

\section{COMPLICATIONS DURING PREGNANCY}

Eclampsia developed in two pregnancies, both of which went to term. One of these was in one of the two patients diagnosed with AIH de novo during pregnancy at 16 weeks' gestation (patient No 15). She was referred from the obstetric department with abnormal biochemical liver tests and pre-eclampsia, with a history of three previous uncomplicated pregnancies. The diagnosis of AIH was made on the basis of serological tests, autoantibody profile, and biochemical response to steroids, and was confirmed after delivery by characteristic liver biopsy findings. Remission was achieved with $17.5 \mathrm{mg} /$ day of prednisolone and subsequently sustained on $7.5 \mathrm{mg} /$ day. The second was in patient 10 who developed eclampsia during her second pregnancy. Her first pregnancy (resulting in twins) had been uncomplicated.
One of the two women who conceived by in vitro fertilisation, and who had no previous history of liver disease, was the second patient (No 18) who presented with de novo AIH and established cirrhosis at 24 weeks' gestation. Decompensation of her liver disease required admission to the liver intensive care unit. Immunosuppressive therapy was not instituted because the clinical situation was considered critical and there were concerns that high dose corticosteroids could be potentially fatal in the setting of overwhelming sepsis. An emergency caesarean section was required at 28 weeks' gestation but the child has had serious physical and mental developmental difficulties since birth. The mother survived and her AIH appeared to enter remission spontaneously. Recently, a second successful in vitro fertilisation in this patient resulted in fetal loss at 20 weeks' gestation associated with infection of the placenta with streptococcus species. Subsequently, however, she has had a relapse of her $\mathrm{AIH}$ and has required prednisolone to maintain remission. The only other complications of pregnancy in the remaining cases related to premature labour in two (patient Nos 7 and 17 ), one at 34 weeks' and the other at 37 weeks' gestation. The reasons for these were unclear

Table 1 Details of pregnancies and immunosuppression regimens in 18 patients with AIH who carried their pregnancies beyond 20 weeks' gestation

\begin{tabular}{|c|c|c|c|c|c|c|c|c|}
\hline \multirow[b]{2}{*}{ Patient } & \multirow[b]{2}{*}{$\begin{array}{l}\text { Age }(y) \text { at } \\
\text { diagnosis }\end{array}$} & \multirow[b]{2}{*}{ Cirrhosis } & \multirow[b]{2}{*}{$\begin{array}{l}\text { Pregnancy } \\
\text { No }\end{array}$} & \multirow[b]{2}{*}{$\begin{array}{l}\text { Age (y) at } \\
\text { conception }\end{array}$} & \multicolumn{2}{|c|}{$\begin{array}{l}\text { Immunosuppressive } \\
\text { therapy at conception }\end{array}$} & \multirow[b]{2}{*}{$\begin{array}{l}\text { Aza } \\
\text { withdrawn }\end{array}$} & \multirow[b]{2}{*}{ Comments } \\
\hline & & & & & $\begin{array}{l}\text { Aza } \\
(m g / \text { day })\end{array}$ & $\begin{array}{l}\text { Pred } \\
\text { (mg/day) }\end{array}$ & & \\
\hline \multirow[t]{2}{*}{1} & 16 & No & 1 & 23 & 75 & 7.5 & No & \\
\hline & & & 2 & 26 & 75 & 7.5 & No & \\
\hline \multirow[t]{2}{*}{2} & 6 & No & 1 & 18 & 0 & 0 & N/A & No treatment for $7 \mathrm{y}$ pre-conception. \\
\hline & & & 2 & 21 & 0 & 0 & N/A & No treatment for 10 y pre-conception. \\
\hline 3 & 25 & No & 1 & 26 & 75 & 7.5 & No & \\
\hline \multirow[t]{2}{*}{4} & 18 & No & 1 & 32 & 75 & 7.5 & No & $\begin{array}{l}\text { Postpartum flare following non-compliance with } \\
\text { therapy. }\end{array}$ \\
\hline & & & 2 & 35 & 75 & 7.5 & No & \\
\hline \multirow[t]{3}{*}{5} & 20 & Yes & 1 & 27 & 0 & 10 & Yes & $\begin{array}{l}\text { Aza withdrawn } 18 \text { months pre-conception. } \\
\text { Postpartum flare. }\end{array}$ \\
\hline & & & 2 & 29 & 100 & 0 & No & Postpartum flare. \\
\hline & & & 3 & 33 & 0 & 10 & Yes & Aza withdrawn 3 months pre-conception. \\
\hline 6 & 23 & Yes & 1 & 33 & 75 & 0 & No & $\begin{array}{l}\text { GI bleed at } 32 \text { weeks. Second GI bleed and death } \\
6 \text { months post partum. }\end{array}$ \\
\hline \multirow[t]{2}{*}{7} & 33 & No & 1 & 34 & 0 & 0 & N/A & $\begin{array}{l}\text { Refused treatment prior to conception. Pred } \\
\text { started at } 16 \text { weeks' gestation because of flare. }\end{array}$ \\
\hline & & & 2 & 36 & 0 & 7.5 & $\mathrm{~N} / \mathrm{A}$ & Delivery at 34 weeks. \\
\hline 8 & 23 & No & 1 & 28 & 75 & 10 & No & \\
\hline \multirow[t]{3}{*}{9} & 16 & No & 1 & 23 & 125 & 0 & No & \\
\hline & & & 2 & 25 & 125 & 0 & No & \\
\hline & & & 3 & 26 & 125 & 0 & No & Maternal and fetal death at 25 weeks. \\
\hline \multirow[t]{2}{*}{10} & 16 & Yes & 1 & 24 & 0 & 10 & Yes & $\begin{array}{l}\text { Twin delivery. Aza withdrawn } 2 \text { y prior to } \\
\text { conception. }\end{array}$ \\
\hline & & & 2 & 32 & 0 & 0 & N/A & $\begin{array}{l}\text { Toxaemia. No treatment for } 3 \text { months prior to this } \\
\text { conception. }\end{array}$ \\
\hline 11 & 19 & Yes & 1 & 29 & 0 & 12.5 & N/A & Conceived by IVF. Postpartum flare. \\
\hline 12 & 16 & Yes & 1 & 30 & 75 & 10 & No & \\
\hline \multirow[t]{2}{*}{13} & 3 & No & 1 & 27 & 0 & 0 & N/A & No treatment for $12 \mathrm{y}$ prior to conception. \\
\hline & & & 2 & 29 & 0 & 0 & N/A & No treatment for 14 y prior to conception. \\
\hline \multirow[t]{3}{*}{14} & 19 & No & 1 & 24 & 0 & 15 & N/A & Flare during first trimester. \\
\hline & & & 2 & 27 & 100 & 7.5 & Yes & Aza withdrawn at 12 weeks' gestation. \\
\hline & & & 3 & 33 & 50 & 5 & No & \\
\hline 15 & 24 & Yes & 1 & 24 & 0 & 0 & N/A & $\begin{array}{l}\text { Toxaemia. De novo presentation with AIH at } 16 \\
\text { weeks' gestation. }\end{array}$ \\
\hline 16 & 18 & Yes & 1 & 20 & 0 & 5 & N/A & \\
\hline \multirow[t]{2}{*}{17} & 27 & No & 1 & 29 & 0 & 0 & N/A & $\begin{array}{l}\text { On treatment with cyclosporin. Pred instituted } \\
\text { during second trimester because of flare. }\end{array}$ \\
\hline & & & 2 & 32 & 50 & 0 & Yes & $\begin{array}{l}\text { Aza withdrawn at } 12 \text { weeks' gestation. Flare } \\
\text { during third trimester. Delivery at } 37 \text { weeks. }\end{array}$ \\
\hline \multirow[t]{2}{*}{18} & 28 & No & 1 & 28 & 0 & 0 & N/A & $\begin{array}{l}\text { Conceived by IVF. De novo presentation with } \\
\text { severe AIH at } 24 \text { weeks' gestation. Caesarean } \\
\text { delivery at } 28 \text { weeks. }\end{array}$ \\
\hline & & & 2 & 30 & 0 & 0 & N/A & $\begin{array}{l}\text { Conceived by IVF. Fetal loss at } 20 \text { weeks' } \\
\text { gestation. }\end{array}$ \\
\hline
\end{tabular}

Aza, azathioprine; pred, prednisolone; IVF, in vitro fertilization; N/A, not applicable; flare, exacerbation of disease as defined in materials and methods. 
but both deliveries occurred during the mothers' second pregnancies, which were otherwise uncomplicated.

MATERNAL AND FETAL OUTCOMES

Two maternal deaths occurred either during the course of the pregnancies or in the postpartum period. One was a non-cirrhotic patient (No 9) who died in the 25 th week of her third pregnancy as a result of severe pulmonary hypertension due to pulmonary microthrombi. Her liver disease had been well controlled on $125 \mathrm{mg} /$ day of azathioprine $(2 \mathrm{mg} / \mathrm{kg} /$ day $)$ alone. Postmortem examination showed no evidence of venous thrombosis in the legs. The patient had had two uncomplicated pregnancies previously while being maintained on $2 \mathrm{mg} / \mathrm{kg} /$ day of azathioprine alone throughout.

The second death occurred six months post partum following an uncontrollable gastrooesophageal variceal bleed. This patient (No 6) was known to have cirrhosis with severe portal hypertension and had been advised against pregnancy. She had also had a variceal bleed at 32 weeks' gestation, without untoward effects on the fetus. Of the remaining 16 women, one (patient No 11) died three years after giving birth, one year after orthotopic liver transplantation for end stage $\mathrm{AIH}$, and a second (patient No 12) died two years after her pregnancy as a result of bleeding secondary to portal hypertension. This latter patient refused transfusion with blood or blood products on religious grounds.

Flares in disease activity occurred during four pregnancies. One was in a patient (No 7) with clinically relatively mild disease (despite biochemical and histological activity) who had declined treatment prior to her pregnancy but, following a flare at 16 weeks' gestation, required introduction of prednisolone at 10 $\mathrm{mg}$ /day. A second was in patient No 14 during the first trimester of her first pregnancy, while she was receiving $15 \mathrm{mg} /$ day of prednisolone, but this resolved spontaneously (without an increase in steroid dosage) and she had no flares during her next two pregnancies. The third and fourth instances were in the patient (No 17) who had been maintained on cyclosporin prior to conception. During her first pregnancy, a flare in the second trimester necessitated introduction of prednisolone at doses of up to $30 \mathrm{mg} /$ day. Remission was achieved and sustained post partum on combination therapy. Steroids were subsequently withdrawn and she was maintained on $1 \mathrm{mg} / \mathrm{kg} /$ day of azathioprine alone. However, in her second pregnancy she had a flare during the third trimester (following withdrawal of azathioprine at 12 weeks' gestation) which required reintroduction of steroids. Flares occurred in four other pregnancies within three months post partum. In one instance (patient No 4) this was related to non-compliance with therapy. All responded to reintroduction of prednisolone or an increase in the dosage by a median increment of $7.5 \mathrm{mg}$ /day (range 5$12.5 \mathrm{mg}$ )

The five $(14.3 \%)$ fetal losses recorded (including one termination and two early mis- carriages) have been described above. The 31 surviving children born to these patients have been followed up now for a median of 10 years (range 1.5-16). On the occasion of the last clinic visit by their mothers, or following recent interview with the patients' primary care physicians, abnormalities have been identified in only two children: one boy aged seven years who developed Perthes' disease of the hip, and the physical and mental handicap in the infant delivered by caesarean section described above.

INFLUENCE OF PREVIOUS MATERNAL HISTORY ON OUTCOME

There was nothing in the patients' previous histories that seemed to be predictive of outcome, particularly whether or not they would experience recrudescence of their disease during pregnancy or post partum. Apart from patient Nos 7 and 17, all of the patients whose AIH had been diagnosed before pregnancy had been in complete clinical and biochemical remission for at least one year prior to conception. Patient No 4, who had been frequently non-compliant with treatment, had suffered seven flares during the 14 years preceding her first pregnancy. Although she had a flare after that pregnancy, this was associated with another documented instance of non-compliance with therapy, and she had no flare during or after her second pregnancy. Of the remaining three patients who had pregnancy associated flares, two (Nos 5 and 14) had suffered only one previous flare, and one (No 11) had four, during dose reduction or withdrawal of prednisolone 1-4 years before conception. On the other hand, of the 10 patients who had no flares during or after their pregnancies, two (Nos 1 and 8) had suffered three previous flares, one (No 12) had two, and two (Nos 2 and 16) had one, during steroid dose reduction or withdrawal. Overall, nine $(64.3 \%)$ of the 14 patients in the pregnancy group whose disease had been in remission for at least one year prior to conception had experienced 1-7 (median 2) previous flares. By comparison, recrudescence of disease had occurred on 1-4 occasions (median 2) in 26 $(52.0 \%)$ of the 50 patients in the AIH control group $(p=0.608)$. The mortality rate in the pregnancy group was also not significantly different from that in the control group $(p=0.889)$. Four of the latter died during the study period (one of septicaemia associated with severe Epstein-Barr virus infection, one of gastrointestinal haemorrhage, and two of liver failure), although six others have received liver transplants for end stage disease.

\section{Discussion}

Reduced fertility has been associated with $\mathrm{AIH}^{1213}$ but conception is not uncommon in women whose disease is in remission. However, the risk of an unsuccessful pregnancy has been reported to be high in these patients, with a fetal death rate of $50 \%$ in one series and of $33 \%$ of 36 cases pooled from the literature. ${ }^{12}{ }^{13}$ In the largest previous study, conducted 20 years ago, Steven et al reported 30 pregnancies in 16 women. ${ }^{13}$ Fetal loss was high (23\%) due 
to spontaneous abortions in three instances and elective termination of the pregnancies in four because of the belief that the pregnancy would adversely affect the course of the liver disease. ${ }^{13}$ Among the remaining 23 pregnancies, there were two stillbirths $(9 \%)$ and the neonatal death rate was also $9 \%$. From pooled data, largely prior to 1975 , Steven and colleagues $^{13}$ noted that the abortion rate reported from 36 pregnancies was $11 \%$, termination rate was $6 \%$, perinatal death rate $20 \%$ (from 30 completed pregnancies), and a maternal death rate of $14 \%$ was described, although they reported no maternal deaths in their own series. These previous studies were of women diagnosed as having "chronic active hepatitis" and may have included some patients with liver disease of aetiologies other than AIH.

In the present study of a relatively homogeneous group of patients with definite AIH according to international criteria, ${ }^{24}$ no terminations for clinical management reasons were recorded but there were two maternal deaths $(11 \%)$. However, one of these deaths was due to acute variceal bleeding six months post partum in a patient who had been advised against pregnancy because of her history of severe portal hypertension and previous bleeding from gastro-oesophageal varices, which had been treated by injection sclerotherapy. The other, due to severe pulmonary hypertension, was unexpected (given that the patient had had two uncomplicated deliveries previously) and it is difficult to know whether her liver disease might have contributed to this. There were no perinatal deaths but it is worth noting that the fetal loss rate (including one termination) of $14.3 \%$ is less than that $(33.0 \%)$ reported by Stevens and colleagues ${ }^{13}$ for AIH patients and than the comparable rate $(24.0-29.3 \%)$ reported for diabetic patients in the USA ${ }^{30}$ and north west England. ${ }^{31}$ Two of the fetal deaths in the present study were spontaneous abortions prior to 20 weeks' gestation. This early fetal loss rate may be an underestimate because women with AIH (with or without cirrhosis) tend to become accustomed to erratic menstrual cycles and, certainly in our experience, sometimes may not realise that they have conceived. In earlier series, prematurity was reported to be as high as $30 \%$ and the caesarean section rate up to $26 \%,{ }^{13}$ although the latter was thought to reflect attempts to salvage threatened pregnancies. In the present series, both the frequency of prematurity $(2 / 32,6 \%)$ and the caesarean section rate $(3 \%)$ were low. Comparative data for the general population of England in 1997 are as follows: terminations (all causes) $21.5 \%$, caesarean sections $17.0 \%$, still births $5.4 \%$, perinatal mortality $0.8 \%$, infant mortality $0.6 \% .^{32}$

Other complications during pregnancy were surprisingly few but it is also important to recognise that pregnancy can apparently precipitate previously unsuspected AIH, as evidenced by the de novo diagnosis of the disease in two of the patients in the present series. Indeed, one of these presented with ascites and decompensated liver disease which contributed largely to the fetal complication rate in this study, with the birth of a premature (physically and mentally handicapped) infant by caesarean section and a subsequent fetal death after 20 weeks' gestation (although the latter was unrelated to the patient's initial presentation).

Exacerbations of $\mathrm{AIH}$ during pregnancy were relatively infrequent $(12.5 \%)$ and similar to that reported previously. ${ }^{13}$ However, relapses occurred post partum in four pregnancies $(12.5 \%)$ in three patients whose disease had apparently been well controlled during their pregnancies, although in one case this was due to a documented instance of non-compliance with therapy. Remission was rapidly achieved in all of these cases by reintroducing or increasing the doses of steroids but it is important to recognise that rebounds post partum do occur and that, such is the diversity of the disease in patients who are well controlled during pregnancy, it is difficult to predict such relapses. Why some patients have exacerbation of their AIH during pregnancy while others maintain in remission only to relapse post partum is unclear. These events have been documented not only in $\mathrm{AIH}^{16}$ but also in other autoimmune diseases. ${ }^{33} 34$ It might be expected that the natural mild immunosuppression in the mother that protects the fetus during gestation would favour remission but it is now well recognised that the immunological responses in autoimmune diseases are profoundly affected by the relative concentrations of oestrogen, prolactin, progesterone, and testosterone. ${ }^{35}$ Thus the different outcomes in $\mathrm{AIH}$ patients during and after pregnancy may be related to differential variations in complex hormonal profiles between individuals.

The appropriateness of azathioprine in pregnant patients with AIH is still controversial. The drug has been found to have teratogenic effects in mice and rabbits but not in rats. ${ }^{17} 1836$ The reasons for these species and strain differences are unknown but may be related to differences in metabolism of azathioprine, differentials in tissue sensitivity to the drug or its metabolites, dose related effects, or a combination of these factors. Although azathioprine crosses the placenta ${ }^{24}$ the lack of teratogenicity recorded in newborns suggests that the human fetus is not overtly affected by the drug. ${ }^{37}$ Neither is there evidence of permanent genomic or gonadal damage. Lymphopenia, hypogammaglobulinaemia, and thymic hypoplasia have been reported in children of mothers who have taken azathioprine in addition to prednisolone in pregnancy but these changes have been regarded as reversible. ${ }^{29}$ In the present series, we have found little to suggest that this drug or its metabolites are toxic in pregnancy. Although formal haematological or immunological evaluation was not performed in the children born to the mothers described here, there have been no reports of defective immune responses or other abnormalities attributable to azathioprine in any of the children.

As individuals who are sensitive to azathioprine usually exhibit side effects of the drug within the first few months of commencing therapy, in de novo presentations of $\mathrm{AIH}$ 
during pregnancy it may be prudent to initially achieve remission using steroid monotherapy. However, in patients who become pregnant while taking azathioprine, there is little evidence to suggest that there should be either a dose reduction or drug withdrawal. This is particularly pertinent for patients with established disease in whom azathioprine is critical for the maintenance of remission, because the risk to the fetus of a relapse of AIH during pregnancy is probably greater than that associated with azathioprine therapy. ${ }^{38}$ The doses used to maintain remission, either 1 or 2 $\mathrm{mg} / \mathrm{kg} /$ day, appear not to be harmful to the fetus in either early or late pregnancy. Thus the present observations suggest that termination of pregnancy purely as a prophylactic measure is not mandatory for women who conceive on the drug. Moreover, as patients have often been established on the drug for many years (median 7.2 years in the present cohort) it may be inadvisable to suddenly stop this agent. If discontinuation of azathioprine therapy is contemplated, it should be remembered that the drug is used for its "steroid sparing" effect in AIH and that a compensatory increase in steroid dosage may be required to sustain remission.

Given that no factors could be identified in the present study to predict which patients were likely to experience activation of AIH during their pregnancies, the need for careful surveillance and disease control during pregnancy is emphasised. To use the analogy with another high risk condition such as diabetic patients undergoing pregnancy, in which live births can be expected in up to three quarters of pregnancies, ${ }^{31} 32$ it has been reported that close attention to euglycaemia significantly reduces complications in the newborn. ${ }^{31}$ Thus it could be argued that a similar paradigm should exist with respect to AIH and that, in view of the long experience with drugs such as azathioprine and prednisolone, immunosuppression withdrawal is probably unnecessary and may be detrimental to mother and child.

1 Meyer zum Büschenfelde K-H, Lohse AW, Manns M, et al. Autoimmunity and liver disease. Hepatology 1990;12:35463.

2 Johnson PJ, McFarlane IG. Meeting Report: International Autoimmune Hepatitis Group. Hepatology 1993;18:998Autoin
1005.

3 Czaja AJ. Clinical aspects of autoimmune hepatitis in North America. In: Nishioka M, Toda G, Zeniya M, eds. Autoimmune hepatitis. Amsterdam: Elsevier, 1994:27-43.

4 International Autoimmune Hepatitis Group report: Review of criteria for diagnosis of autoimmune hepatitis. $\mathcal{F}$ Hepatol 1999;31:929-38.

5 Copenhagen Study Group for Liver Diseases. Effect of prednisolone on the survival of patients with cirrhosis of the liver. Lancet $1969 ; \mathbf{i}: 119-21$.

6 Soloway RD, Summerskill WHJ, Baggenstoss AH, et al. Clinical, biochemical and histological remission of severe
chronic active liver disease: a controlled trial of treatments and early prognosis. Gastroenterology 1972;63:820-33.

7 Cook GC, Mulligan R, Sherlock S. Controlled prospective trial of corticosteroid therapy in active chronic hepatitis. $Q$ trial of corticosteroid the $1971 ; 40: 159-85$.

7 Med $1971 ; 40: 159-85$.
8 Murray-Lyon IM, Stern RB, Williams R. Controlled trial of prednisone and azathioprine in active chronic hepatitis. Lancet 1973;1:735-7.
9 Hegarty JE, Nouri-Aria KT, Portmann B, et al. Relapse following treatment withdrawal in patients with autoimmun chronic active hepatitis. Hepatology 1983;3:685-9.

10 Stellon AJ, Keating JJ, Johnson PJ, et al. Maintenance of remission in autoimmune chronic active hepatitis with azathioprine after corticosteroid withdrawal. Hepatology 1988; 8:781-4.

11 Johnson PJ, McFarlane IG, Williams R. Azathioprine for ong-term maintenance of remission in autoimmune hepatitis. N Engl f Med 1995;333:958-63.

12 Whelton MJ, Sherlock S. Pregnancy in patients with hepatic cirrhosis. Management and outcome. Lancet 1968;2:995-

13 Steven MM, Buckley JD, Mackay IR. Pregnancy in chronic active hepatitis. $Q \mathcal{F}$ Med 1979;192:519-31.

14 Mistilis SP, Skyring AP, Blackburn CRB. Natural history of chronic active hepatitis. I. Clinical features, course, diagnostic criteria, morbidity, mortality and survival. Aust Ann Med 1968;17:214-23.

15 Cundy TF, Butler J, Pope RM, et al. Amenorrhoea in women with non-alcoholic chronic liver disease. Gut 1991; 32:202-6.

16 Colle I, Hautekeete M. Remission of autoimmune hepatitis during pregnancy: A report of two cases. Liver 1999;19:557 .

17 Tuchmann-Duplessis H, Mercier-Parot L. Production in rabbits of malformations of the limbs by azathioprine and 6-mercaptopurine. Compt Rend Soc Biol 1966;160:501-6.

18 Rosenkrantz JG, Githens JH, Cox SM, et al. Azathioprine (Imuran) in pregnancy. Am f Obstet Gynecol 1967;97:387.

19 Present DH, Meltzer SJ, Krumholz MP, et al. 6-Mercaptopurine in the management of inflammatory bowel disease: short and long term toxicity. Ann Intern Med 1989;111:641-9.

20 Vender RJ, Spiro HM. Inflammatory bowel disease and pregnancy. F Clin Gastroenterol 1982;4:231-49.

21 Sorokin JJ, Levine SM. Pregnancy and inflammatory bowel disease: a review of the literature. Obstet Gynecol 1983;62: $247-51$

22 Erkman J, Blyth JG. Azathioprine therapy complicated by pregnancy. Obstet Gynecol 1972;40:708-10.

23 Farber M, Kennison RD, Jackson HT. Successful pregnancy after renal transplantation. Obstet Gynecol 1976;48(suppl 1):25-45.

24 Saarikoski S, Seppala M. Immunosuppression during pregnancy: transmission of azathioprine and its metabolites from the mother to the fetus. Am $\mathcal{f}$ Obstet Gynecol 1973;115:1100-6.

25 Hou S. Pregnancy in organ transplant recipients. Med Clin North Am 1989;734:667-83.

26 Davison JM, Dellagrammatikas H, Parkin JM. Maternal azathioprine therapy and depressed haemopoiesis in the babies of renal allograft patients. Br 7 Obstet Gynaecol 1985;92:233-9.

27 Meehan RT, Dorsey JK. Pregnancy among patients with systemic lupus erythematosus receiving immunosuppressive therapy. $\mathcal{F}$ Rheumatol 1987;14:252-9

28 Alstead EM, Ritchie JK, Lennard-Jones JE, et al. Safety of azathioprine in inflammatory bowel disease. Gastroenterology 1990;99:443-6.

29 Dewitte DB, Buick MK, Cyran SE, et al. Neonatal pancytopenia and severe combined immunodeficiency associated with antenatal administration of azathioprine and predwith antenatal administration of
nisone. Pediatrics 1984;105:625-8.

30 Diabetes Control and Complications Trial Research Group. Pregnancy outcomes in the diabetes control and complications trial. Am f Obstet Gynecol 1996;174:1343-53.

31 Cassons IF, Clarke CA, Howard CV, et al. Outcomes of pregnancy in insulin dependent diabetic women: Results of a five year population cohort study. BMF 1997;315:275-8.

32 London: United Kingdom Office for National Statistics. Birth statistics, 1998;Series FM1:No.27.

33 Bakimer R, Cohen J, Shoenfeld Y. What really happens to fecundity in autoimmune diseases? Immunol Allergy Clin North Am 1994;14:701-23.

34 Sammaritano LR, Lockshin MD. Pregnancy loss in autoimmune diseases. Immunol Allergy Clin North Am 1994;14: $803-19$

35 Whitacre CC, Reingold SC, O'Looney PA. A gender gap in autoimmunity. Science 1999;283:1277-8.

36 Thiersch JP. Effect of 6(1-methyl-4-nitroso-5-imidazolyl) mercaptopurine and 2-amino-6-(1-methyl-4-nitroso-5imidazolyl)-mercaptopurine on rat litter in utero. $\mathcal{F}$ Reprod Fertil 1962;4:297-302.

37 Powell EE, Molloy D. Successful in vitro fertilization and pregnancy in a patient with autoimmune chronic active hepatitis and cirrhosis. F Gastroenterol Hepatol 1995;10: 233-5.

38 Witter FR, King TM. Drugs and the management of chronic diseases in the pregnant patient. In: Stern L, ed. Drug use in pregnancy. Balgowlah, Australia: ADIS Health Science Press, 1984;190-211. 